Int. J. Dev. Biol. 63: 429-438 (2019)

https://doi.org/10.1387/ijdb.190192ts

\title{
Small molecules and cell differentiation in Dictyostelium discoideum
}

\author{
TSUYOSHI ARAKI and TAMAO SAITO* \\ Faculty of Science and Technology, Sophia University, Tokyo, Japan
}

\begin{abstract}
Dictyostelium is a microorganism found in soils that are known as the battle fields of chemical warfare. Genome analysis of Dictyostelium revealed that it has great potential for the production of small molecules, including secondary metabolites such as polyketides and terpenes. Polyketides are a large family of secondary metabolites which have a variety of structures. In accordance with their structural variety, polyketides have a plethora of biological activities, including antimicrobial, antifungal, and antitumor activities. Unsurprisingly, they have exceptional medical importance. Polyketides in nature work as protective compounds and /or function in pheromonal communication. Terpenes belong to another family of structurally diverse secondary metabolites which play roles in ecological interactions, including defence against predators and formation of mutually beneficial alliance with other organisms. Polyketides and terpenes work as intra- or inter-species signalling compounds, i.e. they play the role of a chemical language. However, in Dictyostelium, they work as paracrine signalling compounds which control the organism's multicellular morphogenesis. This review is primarily focused on the small molecules that regulate pattern formation in the slug stage of the organism and their biosynthetic pathways. Current in vivo understandings of polyketide DIF-1 induced cell differentiation and DIF-1-dependent/independent pathways are also discussed.
\end{abstract}

KEY WORDS: polyketide, terpene, transcriptional regulation, Type III PKS, bZIP transcriptional factor, STAT

\section{Complexity in a simple pattern}

Cellular slime mold, Dictyostelium, lives in soil as isolated amoeba eating bacteria. Once surrounding bacterial food source is depleted, approximately 100,000 Dictyostelium cells start to aggregate by chemotaxis toward cyclic adenosine monophosphate cAMP, form a hemispherical multicellular structure, called mound, and further undergo cell differentiations and morphogenic transformations. Resulting terminal structure, fruiting body, consists of two major cells: spore and stalk. Spores are dormant cells protected against various environmental stresses, and stalk is formed by vacuolated dead cells lifting up the spore mass on top of the structure.

This simple-looking final structure conceals their complex and sophisticated developmental program. In the mound, cells commence cell differentiation in "Salt and Pepper" fashion (Thompson et al., 2004; Kay and Thompson, 2009). Cell sorting and threedimensional morphogenetic movement make a clear pattern along anterior-posterior axis in following slug-shaped structure; anterior one-fourth of cells are prestalk cells which will terminally differentiate into stalk cells in fruiting body, and posterior three-fourth are prespore cells which will be spores (Bonner and Slifkin, 1949). This prestalk and prespore ratio is tightly controlled in the slug. Formed slug behaves like a multicellular organism; slug migrates towards light and heat to find suitable place for the fruiting formation (Raper, 1940) and is even equipped with immune system-like defence mechanism (Chen et al., 2007).

The most well-studied intracellular signalling molecule in Dictyostelium is cAMP (3',5'-cyclic adenosine monophosphate). Extracellular CAMP signal is tightly regulated by the combinations of three adenylyl cyclases (ACA, ACB, and ACG: Kriebel and Parent, 2004), four cAMP receptors (CAR1-4; Kim et al., 1998; Verkerke-Van Wijk et al., 1998), and three phosphodiesterases (PdsA/PDE1, PDE4, and 7: Barder et al., 2007), and controls vari-

\footnotetext{
Abbreviations used in this paper: ALC, anterior like cell; cAMP, 3'5'-cyclic adenosine monophosphate; DIF, differentiation inducing factor, 1-[(3,5-dichloro-2,6- dihydroxy-4-methoxy)phenyl] hexan-1-one; DQ, dictyoquinone, 2-hydroxy-5-methyl6-pentylbenzoquinone; ecm, extracellular matrix; MPBD, 4-methyl-5-pentylbenzen-1,3-diol; PKS, polyketide synthase; Psp, prespore; Pst, prestalk; THPH, (2,4,6-trihydroxyphenyl)-1-hexan-1-one.
} *Address correspondence to: Tamao Saito. Faculty of Science and Technology, Sophia University, Tokyo 102-8554, Japan. E-mail: tasaito@ sophia.ac.jp
Tel: +81-3-3238-3366. Fax: +81-3-3238-3361 - (iD) https://orcid.org/0000-0003-0368-4244

Submitted: 1 June, 2019; Accepted: 5 July, 2019.

ISSN: Online 1696-3547, Print 0214-6282 
A

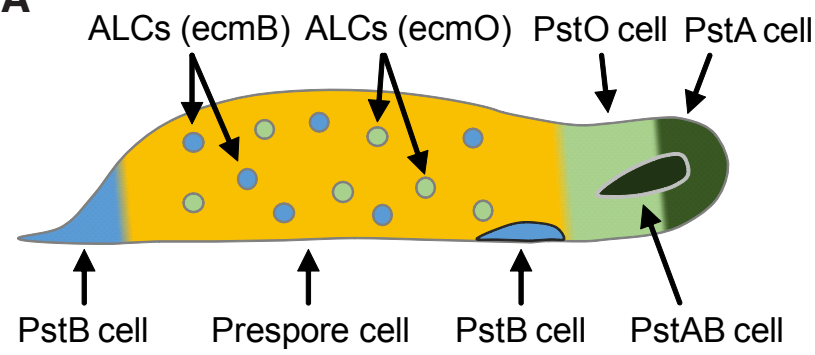

B

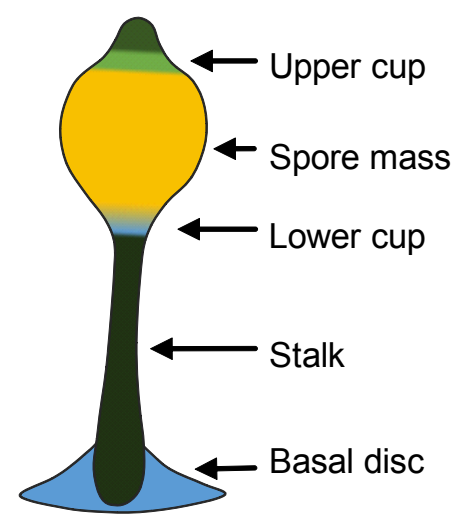

Fig. 1. Schematic drawings represent major cell sub-types at two multicellular stages in Dictyostelium development: migrating slug (A) and fruiting body (B). Each cell sub-type is indicated with different colour. At the fruiting body formation, stalk formation occurs at the core of prestalk region (PstAB cell) with reverse fountain manner and spore mass is lifted up on top of the structure. ALCs (ecmO) move upward and ALCs (ecmB) downward, forming supporting structures of Spore mass, Upper cup and Lower cup respectively. Two PstB cell populations in slug differentiate into Basal disc in fruiting body. Recently-identified two prestalk cell sub-types, PstU and PstVA are not included in these drawings and are described in main text and in Figures 4 and 5.

ous developmental processes. While nanomolar cAMP oscillatory signal works as chemotaxis signal in aggregation, extracellular cAMP concentration is elevated in multicellular structure and micromolar CAMP regulates morphogenesis and cell differentiation (Schaap et al., 1986; Pitt et al., 1993). Prestalk and prespore cells at mound stage have different response to cAMP, resulting in cell sorting to form antero-posterior prestalk/prespore pattern in slug (Sternfeld and David, 1981; Traynor et al., 1992; Dormann et al., 2000). In vitro monolayer assays revealed that cAMP signal induces a number of prespore genes (Mehdy et al., 1983; Schaap and van Driel, 1985), and cAMP at first induces the competency for stalk cell differentiation and later inhibits the stalk cell formation (Berks and Kay, 1988; Soede et al., 1996). Series of in vitro monolayer results indicate that the stalk cells are induced by the combination of cAMP and a low molecular weight, developmentally regulated molecule, differentiation inducing factor (DIF) (Kay, 1981). Further details about cAMP signaling in Dictyostelium are discussed in other reviews of this special issue.

Since the identification of polyketide DIF-1 \{1-[(3,5-dichloro-2,6dihydroxy-4-methoxy)phenyl]hexan-1-one $\}$ as stalk cell inducer, the molecular mechanism of cell differentiation has been studied.
EcmA and ecmBgenes, both encode extracellular matrix proteins, are identified as DIF-1 inducible and prestalk specific genes. EcmA promoter drives strong gene expression in virtually entire prestalk region (PstAO cells; Williams et al., 1989) and, therefore, has been widely used as prestalk marker. Promoter analysis revealed that ecmA promoter (referred to as ecmAO promoter) can be divided into two, cap-site proximal and distal, regions (Early et al., 1993). Cap-site proximal half (ecmA promoter) regulates the expression in cells at anterior half of prestalk (PstA cells). Distal half region (ecmO promoter) directs expression in cells at posterior half of prestalk region (PstO cells) and also in cells at scattered position in prespore region (Anterior-Like-Cells: ALCs). In the process of fruiting body formation, ALCs move upward to make cup-shaped structure (upper cup) which supports and also pushes the spore mass up. EcmB expressing cells are observed at scattered in prespore region (ALCs) and also at the ventral surface (PstB cells) and the rear end (Rear-guard cells) of slug (Ceccarelli et al., 1991). Contrary to ecmO expressing ALCs, ecmB positive ALCs form lower cup, supporting structure at the bottom of the spore mass in the fruiting body. Ventral ecmB-positive cells (PstB cells and Rear-guard cells) differentiate into basal disc, supporting structure of whole fruiting body at the bottom of stalk. Both ecmA and ecmB genes are strongly expressed in the cells at the cone-shaped core (PstAB cells) of the prestalk region, where stalk formation occurs with reverse fountain manner at the onset of fruiting body formation (Ceccarelli et al., 1991). On the other hand, prespore cells at the posterior of slugs are repressed by DIF-1 signal (Early and Williams, 1988) and are thought to be uniform, although gradient prespore specific SP60 gene expression is reported in its anterior-posterior axis (Haberstroh and Firtel, 1990). Fig. 1 shows a schematic representation of cell sub-types in migrating slugs $(A)$ and fruiting body (B).

Analysis of just two DIF-1 inducible and prestalk cell specific genes tells us the complexity of cell population in Dictyostelium. Microarray and subsequent whole-mount in situ hybridization analysis confirmed these prestalk patterns and cell sub-types in the migrating slug (Maeda et al., 2003). At the same time, this work shows the existence of DIF-1-independent mechanism in prestalk cell differentiation and also the dynamic nature of celltype specific gene expression during the developmental process. Understanding diffusible signalling molecules, e.g. DIF-1, MPBD, and Dictyoquinone etc., and their sensing mechanisms can be the keys to understand cell differentiation and pattern formation in Dictyostelium development. A summary of small molecules discussed in this review is shown in Table 1.

\section{DIF-1: biosynthesis and inactivation}

Polyketides comprise a highly diverse class of secondary metabolites found in bacteria, fungi, plants, and animals, and are known to have diverse biological activities and pharmacological properties. Polyketides are synthesized through a decarboxylative condensation (Claisen condensation) using malonyl-CoA as an extension unit. The enzymes that catalyse this condensation reactions are polyketide synthases (PKSs). Genome analysis revealed that $D$. discoideum has 45 putative PKS genes in its genome, of which five appear to be pseudogenes (Eichinger et al., 2005; Zucko et al., 2007). The related species $D$. purpureum is also reported to have a similar number of PKS genes (Sucgang et al., 2011). 
Interestingly, Dictyostelia seem to have a novel type of PKS, the fusion of type I and type III PKSs (Austin et al., 2006). To the best of our knowledge, these fusion-type PKSs are found exclusively in the cellular slime molds. This enzyme is known as Steely (Austin et al., 2006). Steely is basically an iterative type I PKS that has a type III PKS domain in the C-terminal region instead of a thioesterase domain of the enzyme (Figs. $2 \mathrm{~A}$ and $3 \mathrm{~A}$ ).

DIF-1 is one of the most well-characterized differentiationinducing molecules in Dictyostelium. There are many reviews concerning experiments of DIF-1, including some on various biomedical activities in mammalian cell lines (Williams, 2006; Kay and Thompson, 2009; Fukuzawa, 2011; Kubohara and Kikuchi, 2018). Therefore, here we focus on the biosynthetic pathway of DIF-1 and the function of DIF-1, which was revealed by the knockout mutants of biosynthetic enzyme genes (Fig. 2B).

In 1998, three steps of the DIF-1 biosynthetic pathway were proposed and DIF-1 was suggested to be a polyketide (Kay, 1998). Since then, step by step, each biosynthetic enzyme has been reported until a dedicated biosynthetic pathway was completely elucidated (Yellow box in Fig. 2B). In 2000, DmtA, an O-methyltransferase that regulates the final step of DIF-1 biosynthesis, was reported (Thompson and Kay, 2000). A dmtA- mutant is the first example of DIF-1-less mutant that has a defect specifically in DIF-1 biosynthesis. The analysis of this $d m t A$ - mutant showed that DIF-1 induced PstO cells instead of PstA cells to form a major part of the prestalk. Early development of the $d m t A$ - mutant is similar to that of a wild type strain Ax2. The striking feature of DIF-1-less mutant phenotype was found in the slug stage. The $d m t A$ - mutant slugs break up and lay down the stalk behind them like related Dictyostelia D. mucoroides, which produces a stalk continuously during slug migration and fruiting body formation. The $d m t A$ - mutant fruiting bodies also show a clear defect in fruiting body morphology, i.e. slipping down sorus from top of the stalk.

PKS gene producing DIF-1 was identified in 2006 (Austin et al., 2006). SteelyB, one of two hybrid type PKSs, produces (2,4,6-trihydroxyphenyl)-1-hexan-1-one (THPH), which forms a polyketide backbone of DIF-1. In vitro analysis of purified SteelyB type III PKS domain revealed the process of formation of THPH from hexanoyl-CoA and malonyl-CoA. ${ }^{36} \mathrm{Cl}$ labelling showed that stIB- mutant lost the ability to produce DIF-1 and the addition of THPH to these mutant cells restored the production of DIF-1 in vivo. St/B- mutants produced break-up slugs like $d m t A$ - mutants. In the fruiting body stage, st/B-mutant showed clear defects, in that there was a lack of the basal disc which supports the stalk to make an upright fruiting body (Saito et al., 2008). As a result, a stIB- mutant made a slanting fruiting body on the substratum with slipping down sorus, due to the lack of a lower cup that supports the spore head. These phenotypes indicated that $s t / B$ - mutants were lacking a subset of anterior like cells (ALCs) and pstB cells. Analysis on a traction force microscope suggested the mechanism of $s t / B$ - mutant slug disintegration. StIB- mutants lack PstB cells in the posterior part of the slug and hence produce little motive force in the rear region and disintegrate immediately (Rieu et al., 2009). The phenotypic analysis of $d m t A$ - and $s t / B$ - mutants defined the DIF-1-less phenotype.

The enzyme responsible for dichlorination of THPH was identified in 2010 (Neumann et al., 2010). The gene coding this enzyme, chIA, was identified by genome mining with the clue from the prokaryotic flavin-dependent halogenase. At first, chlorination of THPH was
TABLE 1

LIST OF SMALL MOLECULES DISCUSSED IN THIS REVIEW

\begin{tabular}{|c|c|c|c|}
\hline Name & Structure & $\begin{array}{l}\text { Dev. } \\
\text { Stage }\end{array}$ & $\begin{array}{c}\text { Proposed functions } \\
\text { in Dictyostelium development }\end{array}$ \\
\hline \multirow[b]{2}{*}{ CAMP } & & Early & $\begin{array}{l}\text { - Chemoattractant (at nM order, } \\
\text { pulse) }\end{array}$ \\
\hline & & $\begin{array}{l}\text { Mid } \\
+ \\
\text { Late }\end{array}$ & $\begin{array}{l}\text { - Prespore cell induction } \\
\text { - Prestalk cell competency induction } \\
\text { (at mM order, continuous/pulse) }\end{array}$ \\
\hline \multirow[b]{2}{*}{ DIF-1 } & & Early & $\begin{array}{l}\text { - Regulation of chemotactic } \\
\text { response }\end{array}$ \\
\hline & & $\begin{array}{l}\text { Mid } \\
+ \\
\text { Late }\end{array}$ & $\begin{array}{l}\text { - PstB cell and PstO cell regulations } \\
\text { - Prespore cell inhibition } \\
\text { - Autophagic cell death induction }\end{array}$ \\
\hline \multirow{2}{*}{ MPBD } & & Early & $\begin{array}{l}\text { - Regulation of chemotactic } \\
\text { response }\end{array}$ \\
\hline & & Late & - Spore maturation (encapsulation) \\
\hline $\begin{array}{l}\text { Dictyoquinone } \\
\text { (DQ) }\end{array}$ & & $\begin{array}{l}\text { Early } \\
+ \\
\text { Mid }\end{array}$ & $\begin{array}{l}\text { - Regulation of chemotactic } \\
\text { response } \\
\text { - Prespore cell induction } \\
\text { - Cell differentiation competency }\end{array}$ \\
\hline $\begin{array}{l}\text { Discoidol (A)/ } \\
\text { Discodiene } \\
\text { (B) }\end{array}$ & & Late & $\begin{array}{l}\text { - Promotion of fruiting body } \\
\text { formation }\end{array}$ \\
\hline
\end{tabular}

In Dictyostelium development, cAMP (3',5'-cyclic adenosine monophosphate) works not only as intracellular second messenger but also as extracellular signalling molecule in various events with different formats (concentration, signal pattern, and combination with other small molecules). Two hybrid type polyketide synthase (PKS) enzymes, SteelyA (StIA) and SteelyB (StIB), are responsible for the production of DIF-1 \{1-[(3,5-dichloro-2,6-dihydroxy-4-methoxy) phenyl]hexan-I-one $\}$ and MPBD (4-methyl-5-pentylbenzen-1,3,diol), respectively. Dictyoquinone (DQ; 2-hydroxy-5-methyl-6- pentylbenzoquinone), originally identified from its prespore-cell-promoting activity, is a putative MPBD metabolite. Discoidol, a sesquiterpene alcohol, is produced by a terpene synthase, DdTPS8, and a cytochrome P450 enzyme, CYP521A1, catalyzes oxidative degradation of dicoidol to discodiene, a trisnorsesquiterpene.

supposed to be catalysed by chloroperoxidase because the enzymatic activity was stimulated by hydrogen peroxide (Kay, 1998).

The first flavin-dependent halogenase from Pseudomonas was described in 2000 (Keller et al., 2000). Since then, a number of flavin-dependent halogenases were found in prokaryotes and fungi (van Pée and Patallo, 2006; Zeng and Zhan, 2010). The chIAgene is located adjacent to the st/B gene in a head-to-head manner on chromosome 5. The developmental expression profile of $c h / A$ was reported to be identical to that of $s t / B$ and these two genes share a common promoter (Neumann et al., 2010). Therefore, they might be under the same transcriptional regulation.

DIF-1 is made in the prespore region in the slug stage and induces the formation of the prestalk. In this prestalk region, DIF-1 is decomposed and inactivated (Kay and Thompson, 2009). The first step of this inactivation is dechlorination (Kay et al., 1999; Green box in Fig. 2B). The enzyme DIF dechlorinase, DrcA, was identified in 2011(Velazquez et al., 2011). This enzyme was a member of glutathione-S-transferase and catalyses the reductive dechlorination using glutathione. The authors suggest the possibility of the use of these enzymes in bioremediation of halogenated contaminants in the environment.

DIF-1 was first identified in the 1970's and since then it has been 
A SteelyB

\begin{tabular}{|c|c|c|c|c|c|}
\hline KS & AT & $\mathrm{DH}$ & ER & KR & PKS III \\
\hline
\end{tabular}

B

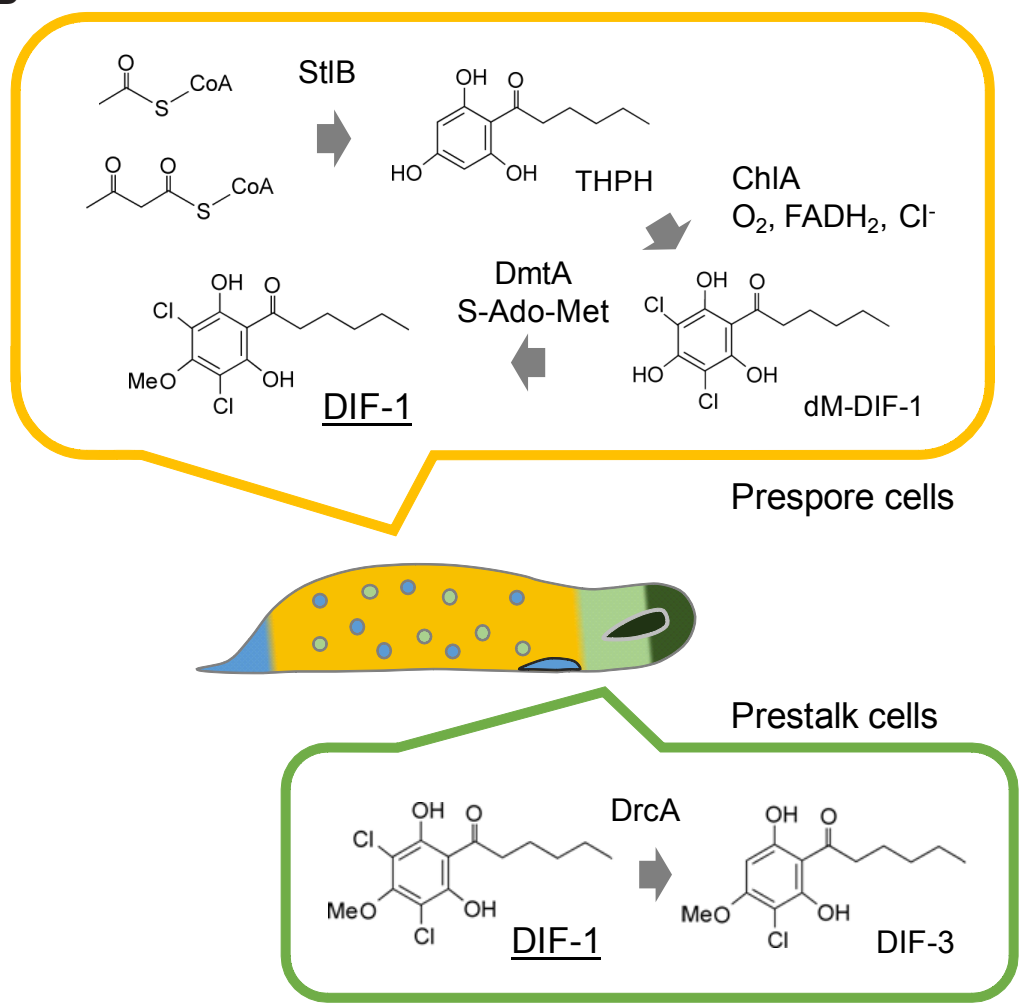

Fig. 2. Structure of SteelyB protein (A) and DIF-1 biosynthesis and degradation (B). (A) Domain structure of SteelyB enzyme consisting of N-terminal type I PKS and C-terminal type III PKS. N-terminal type I PKS constitutes a $\beta$-ketoacyl synthase (KS), an acyltransferase $(A T)$, a dehydratase $(D H)$, an enol-reductase (ER), a keto-reductase $(K R)$, and acyl carrier protein (ACP). C-terminal thioesterase domain of type I PKS is replaced by type III PKS domain in Steely enzyme. (B) The structure and DIF-1 biosynthesis and degradation. DIF-1 biosynthetic pathway consists of three steps. The first step is SteelyB mediated THPH polyketide formation. Second step is ChIA mediated dichlorination and final step is DmtA mediated O-methylation. The first step of DIF-1 degradation pathway is dechlorination mediated by DrcA.

at the centre of developmental biology of Dictyostelium (Kay et al., 1978). Identification of biosynthetic enzymes led us to understand the function of DIF-1 in development. On analysis of biosynthetic enzyme null mutants, to our surprise, it was found that DIF-1 does not induce the differentiation of the major part of the prestalk and stalk cells. This might be due to differences in experimental conditions. In one set of experiments, the DIF activity was analysed by a submerged monolayer assay, which is an in vitro assay (Brookman et al.,1982). However, the developmental morphology was examined with gene knockout mutants, which is an in vivo assay. For example, in submerged monolayer conditions, the cells remained as amoebae and moved in the presence of a polyketide synthase inhibitor, cerulenin (Kay, 1998); while on the agar containing cerulenin, treated cells display normal appearance of fruiting body but with very fragile and single layered stalk tube (Sato et al., 2016).
This means that cerulenin completely inhibited stalk differentiation in submerged monolayer conditions but not in the agar medium containing cerulenin. These differences reflect the differences in experimental conditions. These cerulenin-treated cells developed on cerulenin-containing agar still had ecmA-LacZ-stained cells in the very tip region of the slug (Sato et al., 2016). This indicates that there must be a non-polyketide prestalk inducer in the slug stage. It may be noteworthy to mention early observation that is indicating the existence of additional factor(s) to induce stalk cell in monolayer condition. There shows a difference in stalk cell induction rate between two $D$. discoideium wild-type strains, V12M2 and NC4, in in vitro monolayer condition (Berks and Kay, 1988). NC4 strain, the parent of widely used axenic strains (Ax2, Ax3 and $\mathrm{KAX} 3$ ), requires extra factor(s) (in conditioned medium) in addition to CAMP and DIF-1 to achieve efficient stalk cell differentiation, compared to $\mathrm{V} 12 \mathrm{M} 2$ strain. This still unidentified factor(s) is possibly the one to induce ecmA gene expression in the tip region of the slug.

\section{MPBD: biosynthesis and function}

The compound 4-methyl-5-pentylbenzen-1,3-diol (MPBD) was first identified as a new differentiationinducing factor from the conditioned medium of $\mathrm{HM} 1030$, a $d m t A$ - mutant (Saito et al., 2006). The structure of this new differentiation-inducing factor was confirmed by chemical synthesis. The biological function of MPBD was mysterious. It induced stalk cell differentiation in submerged monolayer assays, but the maximal induction rate was about $20 \%$ and dose response curves were erratic. The analysis of biological function of MPBD had to wait till the identification of the biosynthetic enzyme gene.

When MPBD was identified, it was speculated to be a polyketide based on its structural features, and later another fusion type PKS, SteelyA, was identified to be responsible for the production of MPBD (Narita et al., 2011; Fig. 3A). The phenotypical defects of st/A-mutants were examined to understand the function of MPBD in development. Clear defect was detected in the fruiting body stage. The stIA-mutant cells made a normal stalk and glassy spore head. When examined under a microscope, most of the "spores" remained in the amoebae-like form. Calcofluor staining showed that amoebae-like cells in stlA-mutant lacked encapsulation of spores, due to which few cells were stained. The encapsulation rate was examined by heating at $37^{\circ} \mathrm{C}$ in the presence of EDTA, and about $22 \%$ cells in sorus were encapsulated without MPBD (Narita et al., 2011). Although stlA- mutant showed spore encapsulation defect, expressions of prestalk and prespore marker genes were normal.

StIA- mutant showed another phenotypic defect in the early developmental stage. The development of the mutant was delayed by about $3 \mathrm{~h}$ from the aggregation stage and showed abnormally small aggregation territories. In the st/A- mutant, chemotactic cAMP response was impaired and the cAMP signalling genes were downregulated. The addition of MPBD or endogenous CAMP pulses lacking MPBD rescued the aggregation defect of the stIA- mutant. This indicates that MPBD may act on the same pathway as CAMP 
A SteelyA

\begin{tabular}{|l||l||l|l|l|l|l|l|}
\hline KS & AT & DH & & MT & & ER & KR \\
ACP & PKS III \\
\hline
\end{tabular}

B<smiles>[R]c1cc([R])c([R])c([Z8])c1</smiles><smiles>CCCCCc1cc(O)cc(O)c1C</smiles>

\begin{tabular}{lcccccc}
\hline & $\mathrm{R}^{1}$ & $\mathrm{R}^{2}$ & $\mathrm{R}^{3}$ & $\mathrm{R}^{4}$ & Sporulation & Aggregation \\
\hline MPBD & $\mathrm{OH}$ & $\mathrm{OH}$ & $\mathrm{Me}$ & $\mathrm{Pe}$ & ++ & ++ \\
EPBD & $\mathrm{OH}$ & $\mathrm{OH}$ & $\mathrm{Et}$ & $\mathrm{Pe}$ & - & ++ \\
PPBD & $\mathrm{OH}$ & $\mathrm{OH}$ & $\mathrm{Pr}$ & $\mathrm{Pe}$ & - & - \\
diMe- & $\mathrm{OMe}$ & $\mathrm{OMe}$ & $\mathrm{Me}$ & $\mathrm{Pe}$ & - & + \\
MPBD & $\mathrm{OH}$ & $\mathrm{H}$ & $\mathrm{Me}$ & $\mathrm{Pe}$ & - & + \\
MPP & $\mathrm{OH}$ & $\mathrm{+}$ & + \\
Olivetol & $\mathrm{OH}$ & $\mathrm{OH}$ & $\mathrm{H}$ & $\mathrm{Pe}$ & - & - \\
Orcinol & $\mathrm{OH}$ & $\mathrm{OH}$ & $\mathrm{H}$ & $\mathrm{Me}$ & - & - \\
\hline
\end{tabular}

Fig. 3. Structure of SteelyA protein (A) and effects of MPBD-derivatives on sporulation and aggregation (B). (A) Domain structure of SteelyA enzyme consisting of N-terminal type I PKS and C-terminal type III PKS. $N$-terminal type I PKS constitutes a $\beta$-ketoacyl synthase (KS), an acyltransferase $(A T)$, a dehydratase $(D H)$, a methyltransferase $(M T)$, an enol-reductase $(E R)$, a keto-reductase (KR), and acyl carrier protein (ACP). C-terminal thioesterase domain of type I PKS is replaced by type III PKS domain. (B) Structure of MPBD and its derivatives and effects on sporulation efficiency and on chemotaxis defects in stlA- mutant are shown in the table: $\mathrm{OH}$, hydroxyl group; Me, methyl group; OMe, methoxy group; Et, ethyl group; Pr, propyl group; Pe, pentyl group. The sporulation efficiency of stlA- mutant decreased to about $30 \%$ compared to that of Ax2. The addition of 200 nM MPBD recovered the sporulation efficiency of stIA- mutant to $>70 \%$. Meanwhile all MPBD derivatives, olivetol and orcinol did not affect the sporulation efficiency. Two hundred nanomolar of each chemical compound was added from the initiation of starvation to examine the recovery of cell aggregation of stIA- mutant. The recovery of chemotaxis after treatment with EPBD, PPBD, diMe-MPBD or MPP were confirmed. diMe-MPBD or $M M P$ recovered the chemotaxis of stIA- mutant to $70 \%$ of that for MPBD.

pulse (Narita et al., 2014). The defect of spore encapsulation in stIA- mutants was not rescued by MPBD addition only in the aggregation stage, indicating that the defect of spore encapsulation is not due to the defect of cAMP signalling in the aggregation stage. In fact, the structure-activity relationship study revealed that the functional groups essential for the induction of spore maturation and induction of cell aggregation were different in MPBD molecules (Kondo et al., 2019; Fig. 3B).

The signalling pathway of MPBD for cell aggregation is unknown, but for spore encapsulation was evaluated and G-protein coupled receptor, CrlA, was reported as its receptor (Anjard et al., 2011). In this case, the authors used crlA- mutants with an Ax3 strain background. In order to confirm the signalling pathway of MPBD, the new $c r l A$ - mutant with the Ax2 background, the same parental strain with that of stIA- mutant was created. CrIA- mutant with the Ax2 background showed normal cell aggregation, unlike the stIAmutant. This indicates that MPBD activity in the early development of Ax2 does not require CrlA (Narita et al., 2017).

\section{Psi-factor and dictyoquinone}

Low molecular weight compounds also regulate the differentiation of prespore cells. Psi-factor is a glycoprotein encoded by psiA gene that induces differentiation of prespore cells (Oohata 1995; Nakagawa et al., 1999; Kawata et al., 2004). The other molecule that induces prespore cell differentiation is Polyketide like factor (PLF), also known as Dictyoquinone (DQ). Interestingly, DQ was reported to have $D$-factor activity, which can induce cell aggregation in Polysphondylium violaceum aggregation defect mutant aggA. $D Q$ seems to be a putative MPBD metabolite, because it was reported that synthetic MPBD treated with Frémy's salt gave a good yield of DQ (Takaya et al., 2014). Although there is no report of conversion of MPBD to DQ in vivo, cell aggregation was restored in st/A- cells by addition of DQ but not spore encapsulation. Psi-2 was reported as a prespore cell-inducing factor and it seemed to be a polyketide (Serafimidis and Kay, 2005). Chemical identity of Psi-2 is yet to be elucidated.

\section{Terpene}

Terpenes are also structurally diverse secondary metabolites and are involved in ecological interactions, including defence against predators and formation of mutually beneficial alliance with other organisms. Terpenes are hydrocarbons, constructed from the branched five-carbon skeleton of isoprene which are assembled to each other by various ways. The key enzymes for terpene synthesis are terpene synthases (TPS) and are found only in plants and fungi among eukaryotes. Recent findings indicate a wider distribution of TPS genes in social amoeba (Chen et al., 2016). For example, $D$. discoideum has 11 putative TPS genes in its genome, of which 9 are full-length sequences, while $D$. purpureum genome contains 12 functional TPS genes (Chen et al., 2018). Based on the profiling of volatile compounds by solid-phase microextraction followed by gas chromatography-mass spectrometry, no evidence of volatile terpenes was detected at to stage of $D$. discoideum development. The production of terpenes gradually increased during development. This suggests that terpenes are indeed involved in Dictyostelium development.

In 2019, a novel sesquiterpene alcohol discoidol was identified as a product of DdTPS8 (Chen et al., 2019). A cytochrome P450 enzyme encoding gene, CYP521A1, is located 685 bp away from DdTPS8 in a head-to-head manner on chromosome 6. It turned out that these two genes form a biosynthetic cluster. CYP521A1 catalysed the oxidative degradation of discoidol and formed discodiene, a novel trisnorsesquiterpene. DdTPS8- mutants showed developmental delay from 116 after starvation when the pattern formation of prestalk and prespore occurred. These compounds might, therefore, be involved in the morphogenesis of Dictyostelium.

\section{DIF-1 induced cell differentiation}

Since its biochemical isolation and identification, DIF-1 signal- 
Cell sub-types

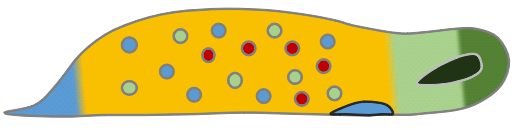

$\operatorname{DimB}$

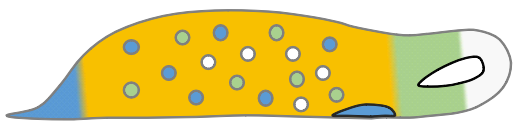

MybE

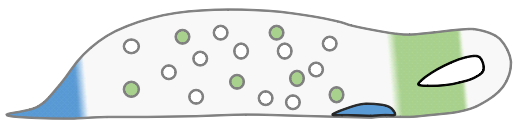

GtaC

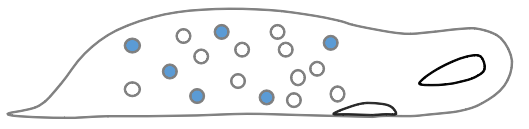

STATC

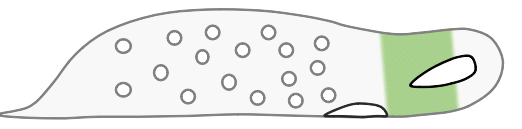

\section{rtaA expression \\ (PstU cell)}

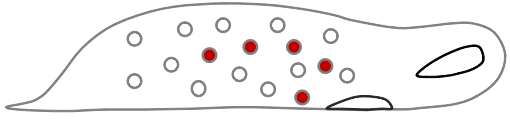

Fig. 4. Complex activation patterns of DIF-1 induced transcriptional activities. Schematic drawings of cell sub-types at which each DIF-1 inducible transcriptional factor (DimB, MybE, GtaC and STATC) and expression of target gene (rtaA gene: PstU cell) are activated. DIF-1 induced activations are observed in multiple cell-types with different combinations throughout migrating slug, except in PstA cells which occupy the anterior half of prestalk region.

ling pathway have been analysed extensively because of its strong stalk cell inducing activity in in vitro monolayer assay. A number of transcriptional factors has been identified and analysed. Fig. 4 shows a schematic representation of the cell-types at where each transcriptional factor is activated by DIF-1.

Two basic leucine zipper (bZIP) family transcriptional factors, DimA and DimB, are involved in DIF-1 signalling pathway (Thompson et al., 2003; Zhukovskaya et al., 2006; Huang et al., 2006). DimB forms heterodimer with DimA and nuclear localises upon the exposure of DIF-1, and $\operatorname{dim} A$ - and $\operatorname{dim} B$ - mutants show similar morphological phenotypes to "DIF less" mutants. In the development, DimB first shows nuclear localization at the mound stage and then becomes highly nuclear enriched in the PstB cells of slug which will form the lower cup and the basal disc of fruiting body (Yamada et al., 2011). DimB directly binds to the ecmB promoter region in response to DIF-1 signal. In addition, these two bZIP transcriptional factors regulate PstO cell differentiation and directly regulate the repression of prespore specific genes, pspA and cotB (Nuñez-Corcuera et al., 2012; Huang et al., 2006).

A single myb domain containing SHAQKY family transcriptional factor, MybE, binds to distal region fragment of ecmA promoter (ecmO promoter) (Fukuzawa etal., 2006). In mybE-mutant, ecmAO expression is tightly restricted in the PstA cells, there are almost no expressions in the regions where is normally occupied by PstO cells and ALCs. EcmB gene is expressed in scattered cells (ALCs) throughout the slug but there is no cone of PstAB cells in anterior prestalk region. Thus, MybE protein is essential for ecmO expressing ALCs formation but not for ecmB expressing ALCs, supporting the previous observations of the heterologous ALCs population (Jermyn and Williams, 1991; Jermyn et al., 1996).

GtaC gene encodes DIF-1 inducible GATA family transcriptional factor. Not only gtaC gene expression is directly regulated by DIF1 , but also GtaC protein accumulate rapidly in response to DIF-1 (Keller and Thompson, 2008). gtaC- mutant is a phenocopy of other DIF-1 signalling mutants: longer and often break-up slugs and no basal disc formation in fruiting body. In gtaC-mutant slug, an increased number of scattered ecmB positive cells (ALCs) exists but clustered ecmB expressing cells at the ventral surface of slug (PstB cells) are not observed. It is suggested that this difference in these two ecmB expressing population observed in gtaC-mutant is due to the impaired cell sorting of PstB cells.

Differential genome-wide microarray analysis of $\operatorname{dim} B$ - and mybE- mutants let us know the depth of DIF-1 signalling pathway (Yamada et al., 2010). RtaA gene is identified as one of the DIF1 inducible genes in $\operatorname{dim} B$ - or $m y b E$ - background, meaning that DimB and MybE both negatively control $r t a A$ and some other DIF-1-inducible genes. RtaA gene is expressed in scattered ALCs at slug stage and preferentially in upper cup at fruiting body. RtaApositive ALCs are distinct from ecmA-positive and ecmB-postive ALCs. This defines new prestalk cell sub-type, PstU cells.

All these prestalk cell sub-types in slug undergo terminal differentiation to vacuolated and dead stalk cells during fruiting body formation. This process is regulated by starvation induced manifestation of autophagosome and following autophagic cell death (ACD) (Giusti et al., 2009). When developing Dictyostelium cells in in vitro monolayer condition are exposed to DIF-1, these cells start forming polarized paddle cells, followed by F-actin depolymerization, vacuolization, and cellulose wall formation; resulting in having similar morphological and physiological features to stalk cells in fruiting body. DIF-1 induced ACD depends on the activation of bZIP transcriptional factors, DimA and DimB (Thompson et al., 2003; Zhukovskaya et al., 2006; Huang et al., 2006), and also autophagy-related protein kinase Atg1 (Luciani et al., 2011), endoplasmic reticulum $\mathrm{IP}_{3}$ gated $\mathrm{Ca}^{2}$ channel IpIA (Lam et al., 2008), and cytoskeletal protein TalB (Giusti et al., 2009).

Taken together, DIF-1 signalling has important roles in PstB, PstO and ALCs differentiation, proportion regulation, and terminal stalk cell differentiation in Dictyostelium. As can be seen from the heterogeneity of ALCs and the new finding of PstU cells, the complexnetwork of transcriptional factors and their upstream regulators does exist in DIF-1 induced cell differentiation.

\section{DIF-1 induced signalling pathways}

How is DIF-1 signal transduced in the cell? Although DIF-1 receptor has not been identified, DIF-1 induced intracellular calcium increase, cytoskeletal changes has been long discussed (Kubohara and Okamoto, 1994; Schaap et al., 1996; Wurster and Kay, 1990). Recent analysis shows that DIF-1 induces significant protein phosphorylation changes.

Phospho-SILAC (Stable Isotope Labelling by Amino acids in Cell culture) approach was used to perform quantitative analysis 
of protein phosphorylation changes in the early response to DIF-1 stimulation (Sugden et al., 2015). The result shows that DIF-1 induces global phosphorylation changes and triggers a major shift toward dephosphorylation. Gene Ontology (GO) analysis revealed that many phosphorylation changes are detected in "Signal transduction cellular response to stimulus", "Cell communications", and "A specific role in GTPase regulator". This analysis provides the evidence that $\mathrm{Ca}^{2+}$ / Calmodulin-dependent phosphatase Calcineurin plays a role in DIF-1 signalling to the bZIP transcriptional factor, DimB (Yamada et al., 2013; Sugden et al., 2015).

One of Dictyostelium STAT(Signal Transducers and Activators of Transcription) protein is also regulated by DIF-1 induced phosphorylation changes. STAT proteins are well-conserved in multicellular organisms and have major roles as a fast-path signalling in response to extracellular stimuli. STATc protein, one of four STAT proteins encoded in Dictyostelium genome, is rapidly activated by tyrosine phosphorylation and nuclear localised upon the stimulation of DIF-1 (Fukuzawa et al., 2001). DIF-1 induces the phosphorylation and inhibition of Protein Tyrosine Phosphatase-3 (PTP3), resulting tyrosine phosphorylation and activation of STATc (Araki et al., 2008). STATc protein is selectively activated in the PstO cells in the slug, and PTP3 overexpressing cells exhibit no STATc nuclear localization in PstO cells and also long and break-up slug phenotype as other "DIF-less" mutants.

DIF-1 induced global de-phosphorylation unveiled new level of DIF-1 signalling network. Function and regulatory mechanism of GTPases have been extensively analysed in the study of Dictyostelium chemotaxis (Charest and Firtel, 2007; Kortholt et al., 2013; Nichols et al., 2019). It is also reported that DIF-1 negatively modulates chemotactic cell movement towards cAMP through the regulation of cGMP phosphodiesterase, GbpB (Kuwayama and Kubohara, 2009). Understanding GTPases and other chemotaxis components may give us a new insight of DIF-1 signalling pathways and, possibly, clues to find DIF-1 receptor.

\section{DIF-1 independent pathways}

As described polyketide DIF-1 has important roles in PstB, PstO and ALCs differentiation, but PstA cell differentiation is not affected by DIF-1 (Thompson and Kay, 2000; Williams, 2006). So, what is the PstA cell inducing factor(s)?

Biochemical purification with PstA-specific (the CA-rich region in cap-site proximal) region of ecmA promoter isolated MrfA protein, Dictyostelium homologue of animal Myelin-gene Regulatory Factor (MRF)-like proteins (Senoo et al., 2012). MrfA protein contains DNA binding domain with high similarity to Yeast Ndt80 sporulation-specific transcription factor. MrfA-mutants show almost no PstA cell differentiation, except at very tip region of the slug. This suggests that PstA cell differentiation is under at least two different regulations: MrfA transcriptional factor-driven mechanism and MrfA-independent tip specific mechanism.

Several lines of evidence suggest that polyketide(s) works on PstA cell differentiation (Sato et al., 2013). By a PKS inhibitor, cerulenin, treatment during development, Dictyostelium cells can form fruiting body, although they look very fragile. PstA cell differentiation in resultant slug is largely suppressed and only

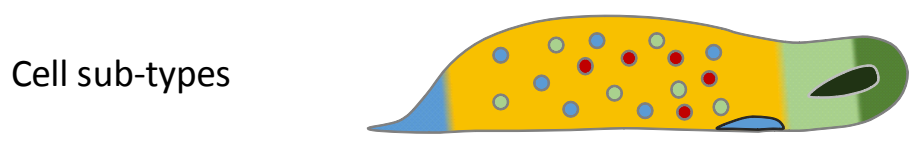

Activated in PstA cells

MrfA

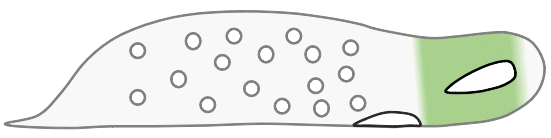

StIA/St|B-produced

polyketide

compound(s)

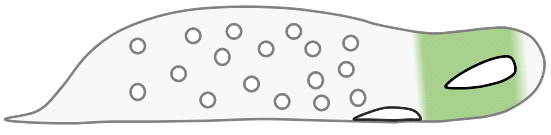

Activated in tip region

ACA (CAMP)

and STATa

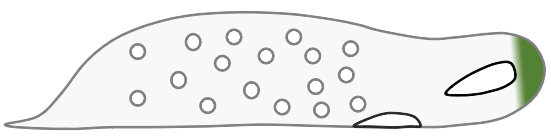

CudA

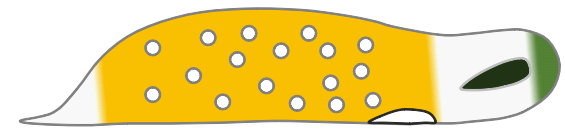

omt12 expression

(PstVA cell)

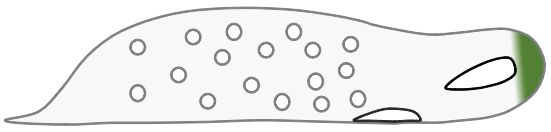

Fig. 5. Activated genes, proteins, and molecules in PstA cells and at the tip region of migrating slug. Although PstA cell inducer(s) and Tip organizer have not been identified, some genes, proteins and molecules have been proposed to be involved. MrfA and unknown polyketide compound(s) produced by two PKSs, StIA and StIB, have roles in most of PstA cell differentiation, but not at the cells in the very tip region of the slug. In the tip region, it is shown that CAMP, produced by Adenylyl cyclase A (ACA), activates STATa protein and STATa protein induces CudA transcriptional factor. Lineage-primed PstVA cells (omt12 expressing cells) also occupy the tip region.

limited to the very tip region of slug. Same phenotype in PstA cell differentiation is observed in double mutant of two PKS enzymes, StIA and StIB. As mentioned above, StIA and StIB produce MPBD and DIF-1 respectively. Interestingly, feeding of neither DIF-1 nor MPBD rescue this defect, while parental cell (Ax2)-released materials restore the PstA cell differentiation partially. These results strongly suggest that a novel polyketide compound(s) produced by two steely enzymes, StIA and StIB, regulates at least some part of PstA cell differentiation and, possibly, the activation of MrfA transcriptional factor.

Yet, we don't have much information about mechanism of PstA cell differentiation in tip region. It is known that slug tip region is functioning as organizer of various morphogenetic multicellular events. Pulsatile cAMP secretion from tip region organises threedimensional cell movement in morphogenesis and slug movement and integrity (Weijer, 2004; Singer et al., 2019). Removal of slug tip makes the halt of slug movement and initiates trans-differentiation and pattern re-formation (Raper, 1940; Sternfeld and David, 1981). Grafting slug tip cells to the rear part of other slug induce splitting 
and formation of new slugs (Raper, 1940). Identity of tip cells is not yet known, thus so-called "Tip organizer" have been defined only as the cluster of cells at the very tip region of slug (Williams, 2006). It is shown that one of the STAT proteins, STATa, and its target gene product CudA, essential transcriptional factor for the initiation of fruiting body formation, are both activated in this region (Verkerke-Van Wijk et al., 2001; Araki et al., 1998; Fukuzawa et al., 1997; Fukuzawa and Williams, 2000). Recent work suggests that expression of O-methyl transferase-12 gene (omt12) shows the lineage-primed cell differentiation and defines a novel prestalk cell sub-type, PstVA at the very tip of PstA cell region (Kuwana et al., 2016). The developmentally-specified PstA and the lineageprimed PstVA, how are these two mechanisms regulated? Does PstVA cells work as Tip organizer? Is there any link between STATa activation and Pst $V^{A}$ cells? Further detailed studies will be needed. Fig. 5 shows a brief summary of activated genes, proteins, and molecules in PstA cells and at the tip region of migrating slug.

\section{Conclusion}

1) The genome data and expression analysis revealed that all PKS and TPS genes are expressed during Dictyostelium development. It appears that Dictyostelium uses these secondary metabolites as signalling molecules to control (multicellular) development rather than chemical communication with its environment.

2) In vivo analysis of DIF-1 shows a glimpse of the depth in its signalling networks at multiple levels. Further investigation of functions and signalling mechanisms of Dictyotelium secondary metabolites will give us clear views of simple yet complex Dictyostelium development.

\section{References}

ANJARD C, SU Y, LOOMIS W F (2011). The polyketide MPBD initiates the SDF-1 signaling cascade that coordinates terminal differentiation in Dictyostelium. Eukaryot Cell 10: 956-963. doi:10.1128/EC.05053-11.

ARAKI T, GAMPER M, EARLY A, FUKUZAWA M, ABE T, KAWATA T, KIM E, FIRTEL RA, WILLIAMS J G (1998). Developmentally and spatially regulated activation of a Dictyostelium STAT protein by a serpentine receptor. EMBO J 17: 4018-4028.

ARAKI T, LANGENICK J, GAMPER M, FIRTEL RA, WILLIAMS J G (2008). Evidence that DIF-1 and hyper-osmotic stress activate a Dictyostelium STAT by inhibiting a specific protein tyrosine phosphatase. Development 135: 1347-1553.

AUSTIN M B, SAITO T, BOWMAN M E, HAYDOCK S, KATO A, MOORE B S, KAY R R, NOEL J P (2006). Biosynthesis of Dictyostelium discoideum differentiationinducing factor by a hybrid type I fatty acid-type III polyketide synthase. Nat Chem Biol 2: 494-502.

BADER S, KORTHOLT, VAN HAASTERT P J M (2007). Seven Dictyostelium discoideum phosphodiesterases degrade three pools of CAMP and cGMP. Biochem J 402: 153-161.

BERKS M, KAY R R (1988). Cyclic AMP is an inhibitor of stalk cell differentiation in Dictyostelium discoideum. Dev Biol 126:108-114.

BONNER J T, SLIFKIN M K (1949). A study of the control of differentiation: the proportions of stalk and spore cells in the slime mold Dictyostelium discoideum. Am J Bot 36: 727-734.

BROOKMAN J J, TOWN C D, JERMYN K A, KAY R R (1982). Developmental regulation of a stalk cell differentiation-inducing factor in Dictyostelium discoideum. Dev Biol 91: 191-196.

CECCARELLI A, MAHBUBANI H, WILLIAMS J G (1991). Positively and negatively acting signals regulating stalk cell and anterior-like cell differentiation in Dictyostelium. Cell 65: 983-989.

CHAREST P G, FIRTEL R A (2007). Big roles for small GTPases in the control of directed cell movement. Biochem J 401:377- 390 .
CHEN G, ZHUCHENKO O, KUSPA A (2007). Immune-like phagocyte activity in the social amoeba. Science 317: 678-681.

CHEN X, KÖLLNER T G, JIA Q, NORRIS A, SANTHANAM B, RABE P, DICKSCHAT J S, SHAULSKY G, GERSHENZON J, CHEN F (2016). Terpene synthase genes in eukaryotes beyond plants and fungi: Occurrence in social amoebae. Proc Natl Acad Sci USA 113: 12132-12137.

CHEN X, KÖLLNER T G, SHAULSKY G, JIA Q, DICKSCHAT J S, GERSHENZON $J$, CHEN F (2018). Diversity and Functional Evolution of Terpene Synthases in Dictyostelid Social Amoebae. Sci Rep 8: 14361. doi:10.1038/s41598-018-32639-0.

CHEN X, LUCKK, RABE P, DINH C Q, SHAULSKY G, NELSOND R, GERSHENZON J, DICKSCHAT JS, KÖLLNERTG, CHENF (2019). Aterpene synthase-cytochrome P450 cluster in Dictyostelium discoideum produces a novel trisnorsesquiterpene. eLife 8: e44352. doi:10.7554/eLife.44352.

DORMANN D, VASIEV B, WEIJER C J (2000). The control of chemotactic cell movement during Dictyostelium morphogenesis. Philos Tran R Soc Lond B Biol Sci 355: 983-991.

EARLY A E, WILLIAMS J G (1988). A Dictyostelium prespore-specific gene is transcriptionally repressed by DIF in vitro. Development 103: 519-524.

EARLYAE, GASKELL M J, TRAYNORD, WILLIAMS J G (1993). Two distinct populations of prestalk cells within the tip of the migratory Dictyostelium slug with differing fates at culmination. Development 118: 353-362.

EICHINGER L et al., (2005). The genome of the social amoeba Dictyostelium discoideum. Nature 435: 43-57.

FUKUZAWA M, HOPPER N, WILLIAMS J G (1997). cudA: a Dictyostelium gene with pleiotropic effects on cellular differentiation and slug behavior. Development 124: 2719-2728.

FUKUZAWA M, WILLIAMS J G (2000). Analysis of the promoter of the cudA gene reveals novel mechanisms of Dictyostelium cell type differentiation. Development 127: 2705-2713.

FUKUZAWAM, ARAKI T, ADRIAN I, WILLIAMS J G (2001). Tyrosine phosphorylationindependent nuclear translocation of a Dictyostelium STAT in response to DIF signaling. Mol Cell 9: 779-788.

FUKUZAWA M, ZHUKOVSKAYA N Z, YAMADA Y, ARAKI T, WILLIAMS J G (2006). Regulation of Dictyostelium prestalk-specific gene expression by a SHAQKY family MYB transcription factor. Development 133: 1715-1724.

FUKUZAWA M (2011). Control of prestalk-cell differentiation by transcription factors. Dev Growth Differ 53: 538-547. doi:10.1111/j.1440-169X.2011.01269.x.

GIUSTIC, TRESSE E, LUCIANI MF, GOLSTEINP (2009). Autophagic cell death: analysis in Dictyostelium. Biochim Biophys Acta 1793: 1422-1431.

HABERSTROH L, FIRTEL R A (1990). A spatial gradient of expression of a cAMPregulated prespore cell-type-specific gene in Dictyostelium. Genes Dev4:596-612.

HUANG E, BLAGG S L, KELLER T, KATOH M, SHAULSKY G, THOMPSON C R L (2006). bZIP transcription factor interactions regulate DIF responses in Dictyostelium. Development 133: 449-458.

JERMYN KA, WILLIAMS J G (1991). An analysis of culmination in Dictyostelium using prestalk and stalk-specific cell autonomous markers. Development 111: 779-787.

JERMYN K A, TRAYNOR D, WILLIAMS J G (1996). The initiation of basal disc formation in Dictyostelium discoideum is an early event in culmination. Development 122: 753 -760.

KAWATA T, NAKAGAWA M, SHIMADA N, FUJII S, OOHATA A A (2004). A gene encoding, prespore-cell-inducing factor in Dictyostelium discoideum. Dev Growth Differ 46: 383-392.

KAY R R, GARROD D, TILLY R (1978). Requirement for cell differentiation in Dictyostelium discoideum. Nature 271: 58-60.

KAY R R (1981). cAMP and spore differentiation in Dictyostelium discoideum. Proc Natl Acad Sci USA 79: 3228-3231.

KAYRR(1998). The biosynthesis of differentiation-inducing factor, a chlorinated signal molecule regulating Dictyostelium development. J Biol Chem 273:2669-2675.

KAY R R, FLATMAN P, THOMPSON C R L (1999). DIF signalling and cell fate. Semin Cell Dev Biol 10: 577-585.

KAY R R, THOMPSON C R L (2009). Forming patterns in development without morphogen gradients: scattered differentiation and sorting out. Cold Spring Harb Perspect Biol 1: a001503. doi:10.1101/cshperspect.a001503.

KELLER $S$ et al., (2000). Purification and partial characterization of tryptophan 7Halogenase (PrnA) from Pseudomonas fluorescens. Angew Chem Int Ed Engl 
39: 2300-2302.

KELLER T, THOMPSON C R L (2008). Cell type specificity of a diffusible inducer is determined by a GATA family transcription factor. Development 135: 1635-1645.

KIM J Y, BORLEIS J A, DEVREOTES P N (1998). Switching of chemoattractant receptors programs development and morphogenesis in Dictyostelium: receptor subtypes activate common responses at different agonist concentrations. Dev Biol 197:117-128.

KONDO A P, NARITA T B, MURATA C, OGURA T, MIKAGI A, USUKI T, SAITO T (2019). 4-Methyl-5-Pentylbenzene-1,3-Diol regulates chemotactic cell aggregation and spore maturation via different mechanisms in Dictyotelium discoideum. Curr Microbiol 76: 376-381. doi:10.1007/s00284-019-01639-2.

KORTHOLT A, KEIZER-GUNNINK I, KATARIA R, VAN HAASTERT P J (2013). Ras activation and symmetry breaking during Dictyostelium chemotaxis. J Cell Sci 126, 4502-4513.

KRIEBEL P W, PARENT C A (2004) Adenylyl cyclase expression and regulation during the differentiation of Dictyostelium discoideum., IUBMB Life 56: 541-546.

KUBOHARA Y, OKAMOTO K (1994) Cytoplasmic $\mathrm{Ca}^{2+}$ and $\mathrm{H}^{+}$concentrations determine cell fate in Dictyostelium discoideum. FASEB J 11: 869-874.

KUBOHARAT., KIKUCHI H (2018) Dictyostelium:An important source of structural and functional diversity in drug discovery. Cells. 8: pii: E6. doi:10.3390/cells8010006.

KUWANA S, SENOO H, SAWAI S, FUKUZAWA M (2016). A novel, lineage-primed prestalk cell subtype involved in the morphogenesis of D. discoideum. Dev Biol 416: 286-299.

KUWAYAMA H, KUBOHARA Y (2009). Differentiation-Inducing Factor-1 and -2 function also as modulators for Dictyostelium chemotaxis. PLoS One 4: e6658. doi:10.1371/journal.pone.0006658.

LAM D, KOSTAA, LUCIANI M F, GOLSTEINP (2008). The inositol 1,4,5-trisphosphate receptor is required to signal autophagic cell death. Mol Biol Cell 19:691-700.

LUCIANI M F, GIUSTIC, HARMSB, OSHIMAY, KIKUCHIH, KUBOHARAY, GOLSTEIN P (2011). Atg1 allows second-signaled autophagic cell death in Dictyostelium. Autophagy 7: 501-508.

MAEDA M, SAKAMOTO H, IRANFAR N, FULLER D, MARUO T, OGIHARA S, MORIO T, URUSHIHARA H, TANAKA Y, LOOMIS W F (2003). Changing patterns of gene expression in Dictyostelium prestalk cell subtypes recognized by in situ hybridization with genes from microarray analyses. Eukaryot Cell 2: 627-637.

MEHDY M C, RATNER D, FIRTEL R A (1983). Induction and modulation of cell-typespecific gene expression in Dictyostelium. Cell 32: 763-771.

NAKAGAWA M, OOHATA A A, TOJO H, FUJII S (1999). A prespore-cell-inducing factor in Dictyostelium discoideum: its purification and characterization. Biochem J 343: 265-271.

NARITA T B, KOIDE K, MORITA N, SAITO T (2011). Dictyostelium hybrid polyketide synthase, SteelyA, produces 4-methyl-5-pentylbenzene-1,3-diol and induces spore maturation. FEMS MicrobiolLett319:82-87. doi:10.1111/j.1574-6968.2011.02273.x.

NARITA T B, CHEN Z H, SCHAAP P, SAITO T (2014). The hybrid type polyketide synthase SteelyA is required for cAMP signalling in early Dictyostelium development. PLoS One 9: e106634. doi:10.1371/journal.pone.0106634.

NARITA T B, SCHAAP P, SAITO T (2017). Effects of deletion of the receptor CrIA on Dictyostelium aggregation and MPBD-mediated responses are strain dependent and not evident in strain Ax2. FEMS Microbiol Lett364. doi:10.1093/femsle/fnx022.

NEUMANN CS, WALSHCT, KAYRR (2010). Aflavin-dependent halogenase catalyzes the chlorination step in the biosynthesis of Dictyostelium differentiation-inducing factor 1. Proc NatlAcad Sci USA 107:5798-5803. Doi:10.1073/pnas.1001681107.

NICHOLS J M E, PASCHKE P, PEAK-CHEW S, WILLIAMS T D, TWEEDY L, SKEHEL M, STEPHENS E, CHUBB J R, KAY R R (2019). The atypical MAP kinase ErkB transmits distinct chemotactic signals through a core signaling module. Dev Cell 48: 491-505.

NUÑEZ-CORCUERA B, BIRCH J L, YAMADA Y, WILLIAMS J G (2012). Transcriptional repression by a bZIP protein regulates Dictyostelim prespore differentiation. PLoS One 7: e29095.

OOHATAAA (1995). Factors controlling prespore cell differentiation in Dictyostelium discoideum: minute amounts of differentiation-inducing factor promote prespore cell differentiation. Differentiation 59: 283-288.

PITT G S, BRANDT R, LIN KC, DEVREOTES P N, SCHAAP P (1993). Extracellular cAMP is sufficient to restore developmental gene expression and morphogenesis in Dictyostelium cells lacking the aggregation adenylyl cyclase (ACA). Genes
Dev 7: 2172-2180

RAPER K B (1940). Pseudoplasmodium formation and organization in Dictyostelium discoideum. J Elisha Mitchell Sci Soc Chapel Hill N C 56: 241-282.

RIEU J P, SAITO T, DELANOË-AYARI H, SAWADA Y, KAY R R (2009). Migration of Dictyostelium slugs: anterior-like cells may provide the motive force for the prespore zone. Cell Motil Cytoskeleton 66: 1073-1086. doi:10.1002/cm.20411.

SAITO T, TAYLOR G W, YANG J C, NEUHAUS D, STETSENKO D, KATO A, KAY R $R$ (2006). Identification of new differentiation inducing factors from Dictyostelium discoideum. Biochim Biophys Acta 1760: 754-761.

SAITO T, KATO A, KAY R R (2008). DIF-1 induces the basal disc of the Dictyostelium fruiting body. Dev Biol317: 444-453. doi:10.1016/j.ydbio.2008.02.036.

SATO Y G, KAGAMI H N, NARITA T B, FUKUZAWA M, SAITO T (2013). Steely enzymes are involved in prestalk and prespore pattern formation. Biosci Biotechnol Biochem 77: 2008-2012.

SATO Y G, SUAREZ T, SAITO T (2016). Stalk cell differentiation without polyketides in the cellular slime mold. Biosci Biotechnol Biochem 80: 1368-1374. doi:10.10 80/09168451.2016.1162087.

SCHAAP P, VAN DRIEL R V (1985). Induction of post-aggregative differentiation in Dictyostelium discoideum by cAMP. Evidence of involvement of the cell surface cAMP receptor. Exp Cell Res 159: 388-398.

SCHAAP P, VAN LOOKEREN-CAMPAGNE M M, VAN DRIEL R, SPEK W, VAN HAASTERT P J M, PINAS J (1986). Postaggregative differentiation induction by cyclic AMP in Dictyostelium: Intracellular transduction pathway and requirement for additional stimuli. Dev Biol 118: 52-63.

SCHAAP P, NEBL T, FISHER P R (1996). A slow sustained increase in cytosolic $\mathrm{Ca} 2+$ levels mediates stalk gene induction by differentiation inducing factor in Dictyostelium. EMBO J 15: 5177-5183.

SENOO H, WANG H Y, ARAKI T, WILLIAMS J G, FUKUZAWA M (2012). An orthologue of the Myelin-gene Regulatory Transcription Factor regulates Dictyostelium prestalk differentiation. Int J Dev Biol 56: 325-332.

SERAFIMIDIS I, KAY R R (2005). New prestalk and prespore inducing signals in Dictyostelium. Dev Biol 282: 432-441.

SINGER G, ARAKIT, WEIJER C J (2019). Oscillatory cAMP cell-cell signalling persists during multicellular Dictyostelium development. Commun Biol. 2:139.

SOEDE R D M, HOPPER N A, WILLIAMS J G, SCHAAP P (1996). Extracellular cAMP depletion triggers stalk gene expression in Dictyostelium: disparities in developmental timing and dose dependency indicate that prespore induction and stalk repression by cAMP are mediated by separate signaling pathways. Dev Biol 177:152-159.

STERNFELD J, DAVID C N (1981). Cell sorting daring pattern formation in Dictyostelium. Differentiation 20: 10-21.

SUCGANG R etal., (2011). Comparative genomics of the social amoebae Dictyostelium discoideum and Dictyostelium purpureum. Genome Biol 12: R20. doi:10.1186/ gb-2011-12-2-r20.

SUGDEN C, URBANIAK M D, ARAKI T, WILLIAMS J G (2015). The Dictyostelium prestalk inducer differentiation-inducing factor-1 (DIF-1) triggers unexpectedly complex global phosphorylation changes. Mol Biol Cell 26: 805-820.

TAKAYA Y, HOTTA R, FUJIWARA K, OTANI R, UCHIYAMA Y, SAKAKIBARA M, FUKUDA E, NIWA M, INOUYE K, OOHATA AA (2014). Alkylbenzoquinone involved in development of cellular slime molds. Org Lett 16: 3660-3663. doi:10.1021/ ol5014119.

THOMPSON C R L, KAY R R (2000). The role of DIF-1 signaling in Dictyostelium development. Mol Cell 6: 1509-1514.

THOMPSON C R L, FU Q, BUHAY C, KAY R R, SHAULSKY G (2003). A bZIP/bRLZ transcription factor required for DIF signaling in Dictyostelium. Development 131: 513-523.

THOMPSON C R L, REICHELT S, KAY R R (2004). A demonstration of pattern formation without positional information in Dictyostelium. Dev Growth Differ46:363-369.

TRAYNOR D, KESSIN R H, WILLIAMS J G (1992). Chemotactic sorting to cAMP in the multicellular stages of Dictyostelium development. Proc Natl Acad Sci USA 79: 3228-3231

VANPÉE KH, PATALO EP (2006) Flavin-dependent halogenases involved in secondary metabolism in bacteria. Appl Microbiol Biotechnol 70:631-641.

VELAZQUEZ F, PEAK-CHEW S Y, FERNÁNDEZ I S, NEUMANN CS, KAY R R (2011). Identification of a eukaryotic reductive dechlorinase and characterization 


\section{T. Araki and T. Saito}

of its mechanism of action on its natural substrate. Chem Biol 18: 1252-1260. doi:10.1016/j.chembiol.2011.08.003.

VERKERKE-VAN WIJKI, KIM JY, BRANDTR, DEVREOTES P N, SCHAAP P (1998) Functional promiscuity of gene regulation by serpentine receptor in Dictyostelium discoideum. Mol Cell Biol 18: 5744-5749.

VERKERKE-VAN WIJK I, FUKUZAWA M, DEVREOTES P N, SCHAAP P (2001). Adenylyl cyclase A expression is tip-specific in Dictyostelium slugs and directs StatA nuclear translocation and CudA gene expression. Dev Biol 234: 151-160.

WEIJERC J (2004). Dictyostelium morphogenesis. Curr Opin Genet Dev14:392-398.

WILLIAMS J G, DUFFY K T, LANE D P et al., (1989). Origins of the prestalk-prespore pattern in Dictyostelium development. Cell 59: 1157-1163.

WILLIAMS J G (2006). Transcriptional regulation of Dictyostelium pattern formation. EMBO Rep 7: 694-698.

WURSTER B, KAY R R (1990). New Roles for DIF? Effects on Early Development in Dictyostelium. Dev Biol 140: 189-195.
YAMADA Y, KAY R R, BLOOMFIELD G, ROSS S, IVENS A, WILLIAMS J G (2010) A new Dictyostelium prestalk cell sub-type. Dev Biol 339: 390-397.

YAMADA Y, NUÑEZ-CORCUERA B, WILLIAMS J G (2011). DIF-1 regulates Dictyostelium basal disc differentiation by inducing the nuclear accumulation of a bZIP transcription factor. Dev Biol 354: 77-86.

YAMADAY, KUBOHARA Y, KIKUCHI H, OSHIMAY, WANG HY, ROSS S, WILLIAMS J G (2013). The Dictyostelium prestalk inducer DIF-1 directs phosphorylation of a bZIP transcription factor. Int J Dev Biol 57: 375-381.

ZENG J, ZHAN J. (2010). A novel fungal flavin-dependent halogenase for natural product biosynthesis. Chembiochem 11:2119-2123. doi:10.1002/cbic.201000439.

ZHUKOVSKAYA N V, FUKUZAWA M, YAMADA Y, ARAKI T, WILLIAMS J G (2006). The Dictyostelium bZIP transcription factor DimB regulates prestalk-specific gene expression. Development 133: 439-448.

ZUCKO J et al., (2007). Polyketide synthase genes and the natural products potential of Dictyostelium discoideum. Bioinformatics 23: 2543-2549. 


\section{Further Related Reading, published previously in the Int. J. Dev. Biol.}

The Dictyostelium prestalk inducer DIF-1 directs phosphorylation of a bZIP transcription factor

Yoko Yamada, Yuzuru Kubohara, Haruhisa Kikuchi, Yoshiteru Oshima, Hong-Yu Wang, Susan Ross and Jeffrey G. Williams

Int. J. Dev. Biol. 57: 375 - 381 (2013)

https://doi.org/10.1387/ijdb.130046jw

An orthologue of the Myelin-gene Regulatory Transcription Factor regulates Dictyostelium prestalk differentiation

Hiroshi Senoo, Hong-Yu Wang, Tsuyoshi Araki, Jeffrey G. Williams and Masashi Fukuzawa Int. J. Dev. Biol. 56: 325 - 334 (2012)

https://doi.org/10.1387/ijdb.120030jw

Identification of a target for CudA, the transcription factor which directs formation of the Dictyostelium tip organiser

Hong-Yu Wang and Jeffrey G. Williams

Int. J. Dev. Biol. 54: 161 - 165 (2010)

https://doi.org/10.1387/ijdb.082723hw

Development at the edge of multi-cellularity: Dictyostelium discoideum.

R R Kay

Int. J. Dev. Biol. 44: 35 - 38 (2000)

http://www.intjdevbiol.com/web/paper/10761844

Regulation of cell differentiation and pattern formation in Dictyostelium development. I Takeuchi, M Tasaka, K Okamoto and Y Maeda Int. J. Dev. Biol. 38: 311 - 319 (1994)

http://www.ijdb.ehu.es/web/paper/7981039
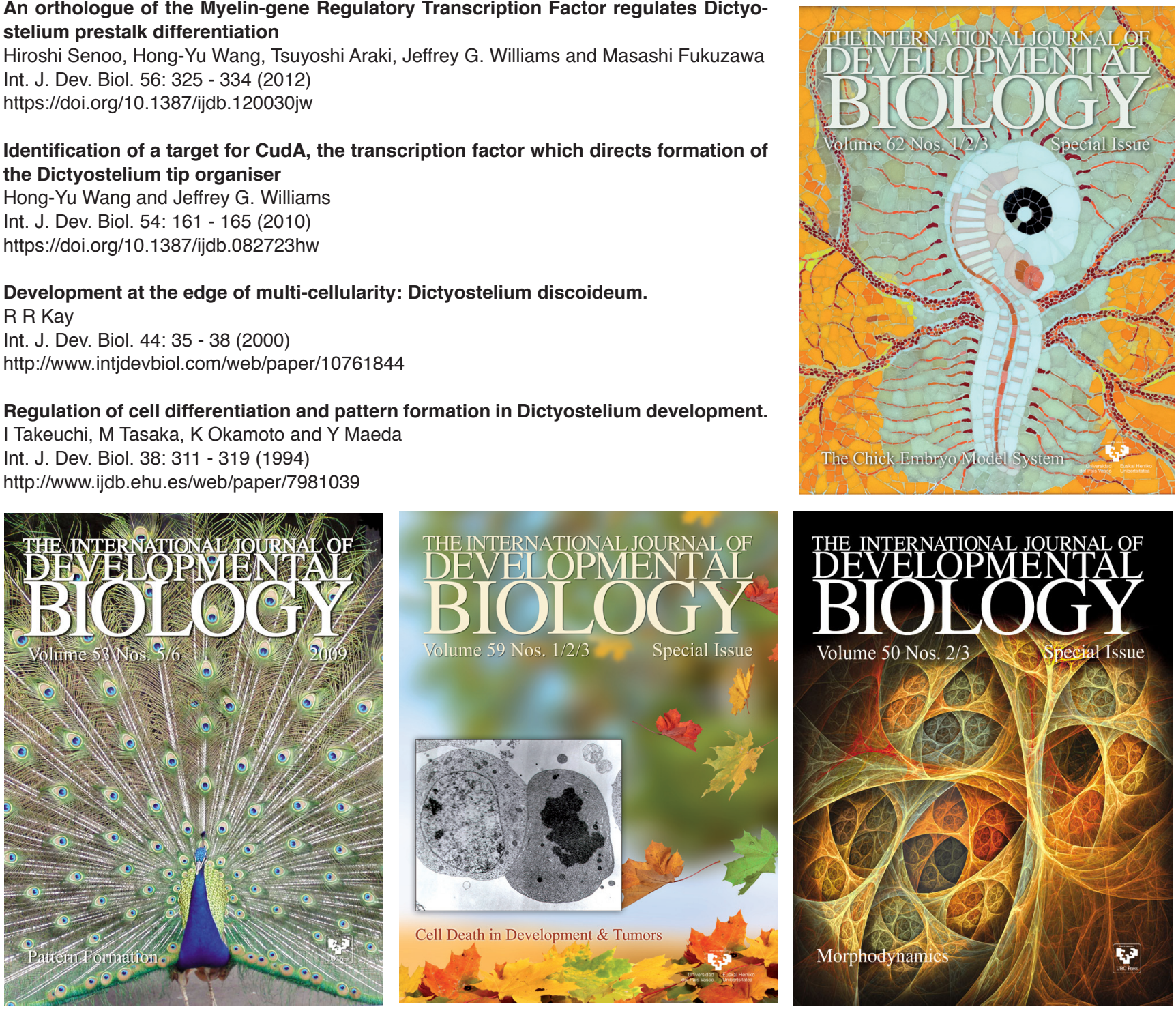